\title{
Enhancing the Pre-Polymerization Coordination of 1-Vinylimidazole
}

Jackie R. Hamilton, Asghar Abedini, Zhongtao Zhang, John W. Whitley, Jason E. Bara, and C. Heath Turner*

Department of Chemical and Biological Engineering, The University of Alabama, Box 870203, Tuscaloosa, AL USA 35487-0203

\begin{abstract}
Recent experimental investigations have found that the rate and conversion of the photopolymerization of 1-vinylimidazole (VIm) can be significantly accelerated with the addition of lithium bistriflimide $\left(\operatorname{LiTf}_{2} \mathrm{~N}\right)$. However, the underlying molecular-level interactions responsible for this phenomenon are unclear. The two components, VIm and $\operatorname{LiTf}_{2} \mathrm{~N}$, are miscible over a wide range of concentrations and form liquid phases at ambient temperature, and if the fundamental behavior of this mixture can be clearly quantified, there are significant opportunities for tuning the polymerization dynamics, polymer structure, and properties. In this work, molecular dynamics (MD) simulations are used to model the underlying pre-polymerization structure of VIm $+\operatorname{LiTf}_{2} \mathrm{~N}$ mixtures at several different concentrations. It is found that the $\mathrm{Li}^{+}$enhances the site-site interactions of key functional groups involved in the polymerization, and this is suggested to play a major role in the experimentally-observed enhancement of the polymerization behavior.
\end{abstract}

KEYWORDS: ionic liquid; polymerization; molecular dynamics; simulation; imidazole

*corresponding author contact information: hturner@eng.ua.edu 205-348-1733 


\section{Introduction}

Poly(vinylimidazole) (poly(VIm)) is a polymer with an imidazole pendant that can be produced via radical polymerization methods as a homopolymer from 1vinylimidazole (VIm) or as a copolymer with co-monomers, such as vinyl acetate, acrylonitrile and divinylbenzene. Poly(VIm) is hydrophilic and features pendant imidazole groups that can act as bases, nucleophiles and/or chelating agents and thus has been investigated for a broad range of applications, such as coating electrodes, ${ }^{1}$ fuel cell membranes, ${ }^{2}$ and separations applications including $\mathrm{CO}_{2}$ adsorption ${ }^{3,4}$ and the adsorption of metal ions. ${ }^{5}$

Recently, we explored the photopolymerization of bulk (i.e. solvent-free) VIm as a means of producing poly(VIm). One of the challenges encountered during the bulk photopolymerization of 1-vinylimidazole is that the polymerization is relatively slow, with an ultimate monomer conversion $~ 80 \%$, which results in $20 \%$ unreacted residual Vim within the poly(VIm). ${ }^{6}$ Such behavior in bulk photopolymerization is not unexpected, as it is well known that such limitations are the consequence of mass transport limitations due to increasing viscosity as the polymer chains grow, and the unreacted monomer diffuses ever more slowly to the propagating radical. ${ }^{6}$

This auto-deceleration effect is the result of poor reactant diffusion, so various methods of monomer organization have been introduced to reduce the effects of mass transfer on polymerization kinetics. ${ }^{7,8,9}$ In addition to several solid state polymerization methods, multiple liquid crystal phases have been used as media for structured

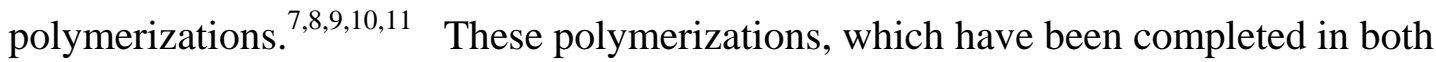
thermotropic and lyotropic liquid crystals, display improved rates of polymerization, with 
the specific kinetic behavior dependent on the degree of order in the liquid crystal phase. $^{12} 13,14,15$

Recently, ionic liquids (ILs) have also received attention as media for radical polymerizations. ILs are typically considered to be salts with melting temperatures below $100^{\circ} \mathrm{C}$ and have many unique and tunable properties that have motivated a great deal of research. ${ }^{16,17,18}$ In addition, both theoretical and experimental studies have demonstrated the ability of these substances to aggregate into polar and non-polar domains at the nanometer scale. ${ }^{19,20}$ As well as their potential applications in organic synthesis, ILs are also attractive as solvents in radical polymerizations due to their ability to increase the rate of propagation and termination of these reactions while also increasing the molecular weight of the resulting polymers. . $1,22,23,24,25,26$

However, few studies have examined the use of ILs containing coordinated ions in polymerization reactions. Past studies have explored the polymerization of methyl methacrylate (MMA), acrylonitrile, and VIm with the addition of Lewis acids with different metal cations. ${ }^{27,28,29}$ These experimental studies have suggested that certain metals are likely to form a ligand complex with monomers and smaller polymer chains in solution, and these specific interactions can enhance the coordination of specific molecules, leading to increased polymerization rates. Lithium bistriflimide $\left(\operatorname{LiTf}_{2} \mathrm{~N}\right)$ is a bulky salt that exhibits significant solubility in organic solvents, and it has been shown to facilitate the polymerization of $\mathrm{MMA}^{30}$ at relatively low concentrations as well as 1vinylimidazole at higher monomer:salt ratios. ${ }^{6}$ Both studies indicate an increase in reaction rate and monomer conversion when $\mathrm{LiTf}_{2} \mathrm{~N}$ is added. 
In this work, we use molecular dynamics (MD) simulations to explore the underlying molecular interactions responsible for the reaction enhancement in mixtures of 1-vinylimidazole (VIm) coordinated to the $\mathrm{LiTf}_{2} \mathrm{~N}$ solvent. In computational studies, the thermophysical properties of ILs have been an important topic for quite some time, and $\operatorname{LiTf}_{2} \mathrm{~N}$ has been modeled many times in solution within ILs. ${ }^{31,32,33}$

(a)

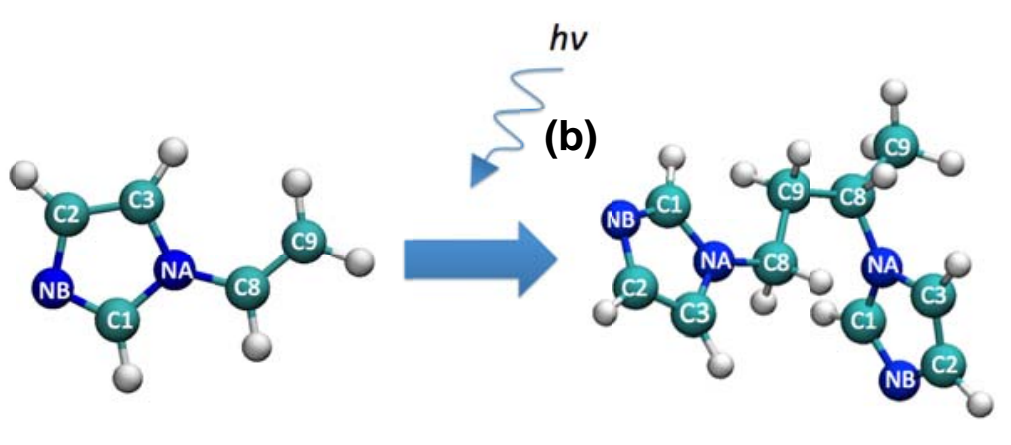

Figure 1. Illustration of the photopolymerization of (a) VIm to (b) a VIm dimer, including the labels of individual sites. The reaction primarily occurs through the C8-C9 sites.

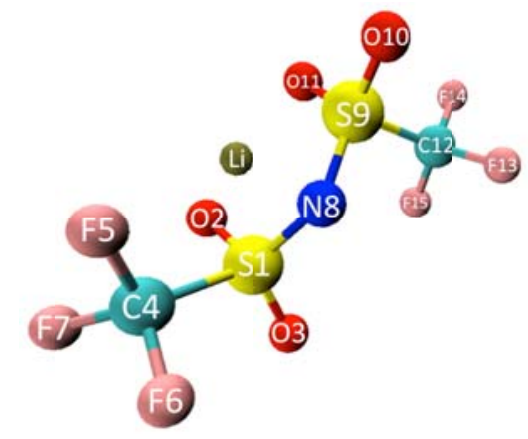

Figure 2. Illustration of the $\operatorname{LiTf}_{2} \mathrm{~N}$ model, including labels of the individual sites.

In this study, eight different mixtures of VIm and $\operatorname{LiTf}_{2} \mathrm{~N}$ solutions were simulated using MD, with molar ratios of VIm to $\operatorname{LiTf}_{2} \mathrm{~N}$ ranging from 1:1 to 10:1. These ratios were chosen based on the availability of experimental data, ${ }^{6}$ which were used as initial simulation benchmarks. By comparing experimental properties to those calculated from the simulations of VIm in solution with $\operatorname{LiTf}_{2} \mathrm{~N}$, refined molecular models are 
generated and used to identify the key interactions in these mixtures, in order to understand the polymerization enhancement.

Using our MD simulations, we find that the $\mathrm{Li}^{+}$cation enhances the local coordination of the VIm monomers, leading to pre-polymerization structures that are likely to favor enhanced polymerization rates and overall monomer conversion due to the proximity of the vinyl groups. In addition, similar simulations were performed by replacing the $\mathrm{Tf}_{2} \mathrm{~N}^{-}$group with two other anions, tetrafluoroborate $\left(\mathrm{BF}_{4}{ }^{-}\right)$and hexafluorophosphate $\left(\mathrm{PF}_{6}{ }^{-}\right)$, in order to compare how VIm and $\mathrm{Li}^{+}$coordinate with different anions. Also $\mathrm{Li}^{+}$was replaced with $\mathrm{Na}^{+}$to compare how the coordination of VIm behaves when exposed to different cations. The comparisons show that higher coordination can occur around the larger cation, but $\operatorname{LiTf}_{2} \mathrm{~N}$ addition still yielded the highest local concentration of VIm molecules in favorable pre-polymerization configurations.

\section{Simulation Methods}

MD simulations were run with Gromacs $4.6 .5^{34}$ and following equilibration, production was allowed to run for $10^{7}$ steps with a time step of $0.001 \mathrm{ps}$, for a total simulation time of $10.0 \mathrm{~ns}$. Pressure was maintained at 1 bar in all simulations using a Parrinello-Rahman barostat, ${ }^{35}$ and the temperature was held fixed using a Nose-Hover thermostat. ${ }^{36}$

The particle-mesh Ewald (PME) ${ }^{37}$ was used for long-range electrostatic interactions with a Coulomb cut-off of $0.9 \mathrm{~nm}$ and Fourier spacing of $0.12 \mathrm{~nm}^{-1}$. Site-site interactions were cut off at $0.9 \mathrm{~nm}$ and standard tail corrections for energy and pressure 
were used to account for dispersion interactions beyond the cutoff. ${ }^{38}$ Parameters for all simulated molecules were described using the OPLS all atom force field ${ }^{39}$ and other sources. ${ }^{40}$ Fixed bond lengths were used for all molecules, and this constraint is expected to result in a negligible loss in accuracy. ${ }^{41}$ The Lennard-Jones potential was used to describe the interactions between atoms, and Lorentz-Berthelot mixing rules were used to account for unlike pair interactions.

The simulations used a fixed charge model on individual atomic sites to represent electrostatic interactions. In order to obtain these partial charges, the electronic structures of VIm and the IL anions were calculated with Gaussian 09. ${ }^{42}$ In the first step, density functional theory (DFT) was used to find the minimum energy configuration, and these calculations were performed using the B3LYP functional ${ }^{43}$ and the 6-31 $\mathrm{g}++(\mathrm{d}, \mathrm{p})$ basis set. This was followed by a natural bond order (NBO) population analysis ${ }^{44}$ at the MP2/6-311++g(3d,3p) level of theory. In order to refine the electrostatic charges to be used in the MD simulations, the NBO charges for VIm from the MP2 calculations were scaled by a factor of $0.8,{ }^{45}$ as well as the charges on the IL cation and anion model (as listed in Tables 1 and 2). Although there are more sophisticated methods for quantifying partial charges in ILs, ${ }^{46,32}$ a fixed scaling factor of 0.8 tends to improve the kinetic and thermodynamic properties (versus using integer charges on the anions and cations). This same scaling factor has also been shown to improve agreement with imidazole-based molecules, when comparing simulated and experimental thermophysical properties. Recent studies have shown that scaling ion charges can help account for the effect of polarizability, and that it is not always necessary to have an integer charge when simulating ion pairs. ${ }^{47}$ Preliminary simulations with integer charges resulted in densities 
that were significantly higher than the experimental data for the corresponding mixtures. $\mathrm{Tf}_{2} \mathrm{~N}$ was modeled as a 15 site charge based models from Zhao et al. ${ }^{48} \mathrm{PF}_{6}$ and $\mathrm{BF}_{4}$ were also assigned partial charges based on models in previous studies. ${ }^{49}$ VIm was modeled as 13 sites and charge neutral.

\section{Results}

The results are presented in three main parts. First, we benchmark simulation data to experimental data of pure components and mixtures. This allowed us to slightly refine our intermolecular potential model. Next, we analyze the local coordination of the VIm monomers with respect to the addition of varying amounts of $\operatorname{LiTf}_{2} \mathrm{~N}$. Finally, we extend our study by examining the local VIm coordination behavior with respect to three other similar salts, including $\mathrm{NaTf}_{2} \mathrm{~N}, \mathrm{LiPF}_{6}$, and $\mathrm{LiBF}_{4}$. 
Table 1. A compilation of the intermolecular parameters used for modeling VIm. The partial charges for VIm in this table were calculated using NBO population analysis and then scaled by a factor of 0.8. The net charge of each molecule is shown in parenthesis.

\begin{tabular}{cccc} 
Site & charge (e) & epsilon (kJ/mol) & sigma (nm) \\
\hline \multicolumn{3}{c}{ VIm (0.0 e $)$} \\
C1 & 0.260 & 0.293 & 0.355 \\
C2 & -0.013 & 0.293 & 0.355 \\
C3 & -0.035 & 0.293 & 0.355 \\
NA & -0.406 & 0.711 & 0.325 \\
H5 & 0.151 & 0.126 & 0.242 \\
H6 & 0.161 & 0.126 & 0.242 \\
NB & -0.446 & 0.711 & 0.325 \\
C8 & 0.068 & 0.318 & 0.355 \\
C9 & -0.325 & 0.318 & 0.355 \\
H10 & 0.146 & 0.126 & 0.242 \\
H11 & 0.153 & 0.126 & 0.242 \\
H12 & 0.144 & 0.126 & 0.242 \\
H13 & 0.142 & 0.126 & 0.242 \\
\hline
\end{tabular}

Table 2. A compilation of the intermolecular parameters used to model the IL molecules. The partial charges in this table reflect data from previous studies scaled by a factor of 0.8 . The net charge on each molecule is shown in parenthesis.

\begin{tabular}{cccc} 
site & charge (e) & epsilon (kJ/mol) & sigma (nm) \\
\hline \multicolumn{4}{c}{$\mathbf{T f}_{\mathbf{2}} \mathbf{N}\left(\mathbf{- 0 . 8} \mathbf{e}^{-}\right)$} \\
S1 & 0.816 & 1.046 & 0.373 \\
O2 & -0.424 & 0.879 & 0.311 \\
O3 & -0.424 & 0.879 & 0.311 \\
C4 & 0.280 & 0.276 & 0.368 \\
F5 & -0.128 & 0.222 & 0.310 \\
F6 & -0.128 & 0.222 & 0.310 \\
F7 & -0.128 & 0.222 & 0.310 \\
N8 & -0.528 & 0.711 & 0.341 \\
S9 & 0.816 & 1.046 & 0.373 \\
O10 & -0.424 & 0.879 & 0.311 \\
O11 & -0.424 & 0.879 & 0.311 \\
C12 & 0.280 & 0.276 & 0.368 \\
F13 & -0.128 & 0.222 & 0.310 \\
F14 & -0.128 & 0.222 & 0.310 \\
F15 & -0.128 & 0.222 & 0.310 \\
\hline \multicolumn{4}{l}{ Hexafluorophosphate (-0.8 e) } \\
\hline
\end{tabular}




\begin{tabular}{cccc}
\hline $\mathrm{P}$ & 1.072 & 0.8368 & 0.3927 \\
$\mathrm{~F}$ & -0.312 & 0.2552 & 0.3276 \\
\hline \multicolumn{5}{c}{ Tetrafluoroborate (-0.8 e-) } \\
\hline $\mathrm{B}$ & 0.941 & 0.3928 & 0.3760 \\
$\mathrm{~F}$ & -0.435 & 0.2552 & 0.3276 \\
\hline \multicolumn{4}{c}{ Cations $\mathbf{( + \mathbf { 0 . 8 }}$ e) } \\
\hline $\mathrm{Li}$ & 0.80 & 0.076 & 0.223 \\
$\mathrm{Na}$ & 0.80 & 0.012 & 0.350 \\
\hline
\end{tabular}

\subsection{Pure $\operatorname{LiTf}_{2} \mathrm{~N}$}

To evaluate the performance of the $\mathrm{LiTf}_{2} \mathrm{~N}$ force field, a pure $\mathrm{LiTf}_{2} \mathrm{~N}$ system was used to compare simulated and experimental densities. $\operatorname{LiTf}_{2} \mathrm{~N}$ has a melting temperature of $507 \mathrm{~K},{ }^{51}$ so to evaluate our intermolecular parameters, simulated densities of pure $\operatorname{LiTf}_{2} \mathrm{~N}$ were compared to an experimental data set over a range of liquid conditions. ${ }^{50}$ The simulated densities for pure $\mathrm{LiTf}_{2} \mathrm{~N}$ using the original parameter set ${ }^{39,48}$ were 6-7\% higher than the experimental values over the temperature range explored. In order to improve the simulation results, a number of different moderate adjustments to the interactions were explored (different charge scaling values, alternate cross-term mixing rules, etc.). Ultimately, the best performance was found by scaling all of the LennardJones sigma values by 1.05 , which led to an overall decrease in the system density. These scaled sigma values are shown in Tables 1 and 2, and these refined values are used throughout this work. As shown in Figure 3, the simulated densities using the refined parameters for $\operatorname{LiTf}_{2} \mathrm{~N}$ fall within less than $1 \%$ of the experimentally-measured densities. Similar methods have been used for refining simulation parameters for ionic mixtures. ${ }^{52}$, 53

The structural analyses presented in the remainder of the paper have also been performed with the original force field. However, only very slight variations in the 
results were detected (data omitted for clarity). For instance, using the original force field parameters, the position of the first peak in the C8-C9 RDF plots (Figure 6) is increased by $1-2 \%$ and the height of the first peak is increased by $2-3 \%$. In the $\mathrm{Li}^{+}-\mathrm{NB}$ RDF plots (Figure 7), the original parameter set yields a first peak position at a distance 2-3\% closer and a peak height 2-3\% lower. Thus, while the updated parameters shifted the densities to be more consistent with the experimental results, only very small differences were measured in the other fluid structural properties. All of the trends in the structural data of the new force field were very consistent with original parameters set. This seems reasonable, since all of the sigma values were consistently scaled, and the scaling value was relatively small (5\%). In addition, due to Lorentz-Berthelot mixing rules implemented during the simulations, the net impact of the updated force field was relatively small. Although we did not explore other thermodynamic properties, it is possible that there could be other unexpected effects (heat capacity, vapor pressure, etc.). While more comprehensive model evaluations may be possible with additional experimental data, an improvement in the density prediction was interpreted to be a satisfactory outcome, especially considering the structural information probed in the current study. As more experimental data becomes available, additional benchmarking studies are anticipated to lead to further model improvements. 


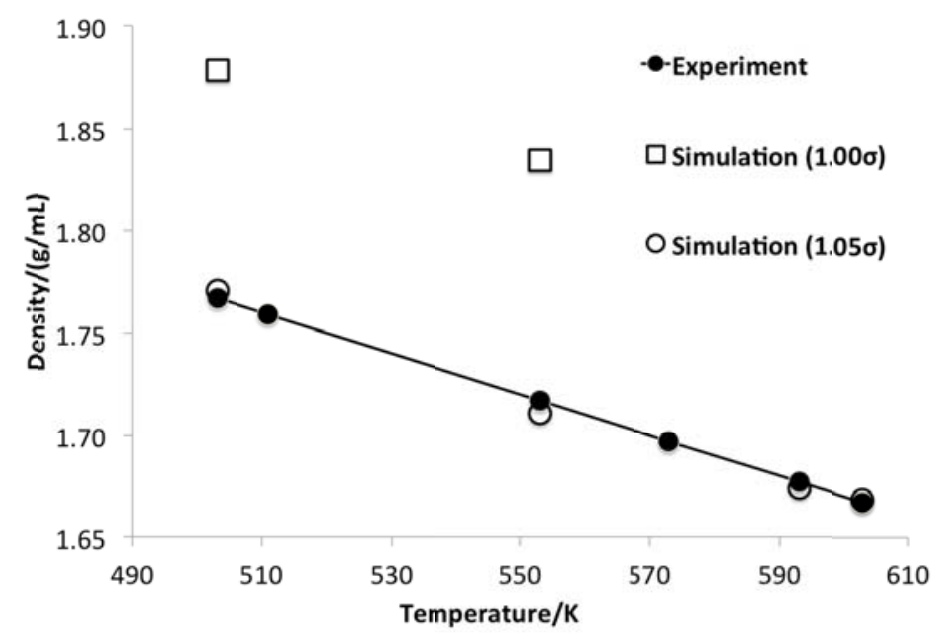

Figure 3. Density of pure $\operatorname{LiTf}_{2} \mathrm{~N}$ with respect to temperature for the original and for the scaled Lennard-Jones potentials (shown in Table 2). By scaling the sigma value for each atom by 1.05, the simulated density is consistent with the experimentally-measured density. ${ }^{50}$

Following the parameter refinement, simulations of $\operatorname{LiTf}_{2} \mathrm{~N}$ in water were also conducted, in order to perform additional benchmarking against experimental densities. ${ }^{6}$ The refined charges and LJ parameters listed in Table 2 were used for $\operatorname{LiTf}_{2} \mathrm{~N}$, and the water molecules were described by the SPC intermolecular potential. ${ }^{54}$ Figure 4 shows that the comparison between simulation and experimental densities is very good $(<2 \%$ error) over a fairly broad range of $\mathrm{LiTf}_{2} \mathrm{~N}$ concentrations.

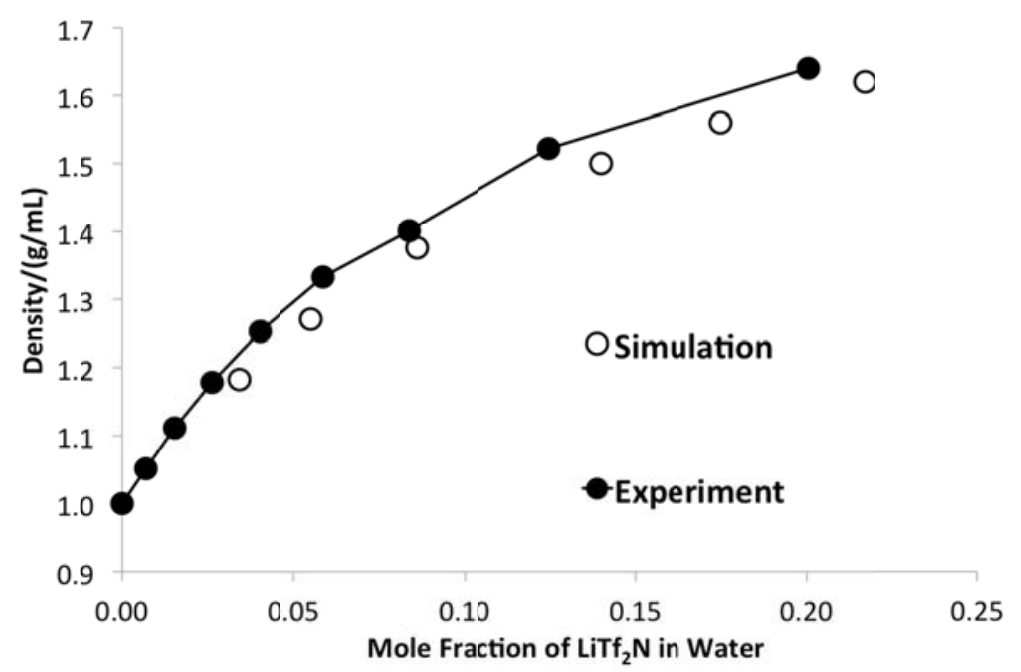

Figure 4. Comparison of experimental and simulation densities of mixtures of $\operatorname{LiTf}_{2} \mathrm{~N}$ and SPC water at a temperature of $303 \mathrm{~K}$. 


\subsection{Mixtures of VIm $+\operatorname{LiTf}_{2} \mathrm{~N}$}

After the intermolecular parameters for $\operatorname{LiTf}_{2} \mathrm{~N}$ were benchmarked against the pure liquid and against aqueous $\operatorname{LiTf}_{2} \mathrm{~N}$ mixtures, simulations were performed for the $\mathrm{VIm}+\mathrm{LiTf}_{2} \mathrm{~N}$ mixtures. Before performing detailed analysis of the liquid structure and site-site interactions, the simulated densities were again compared against experimentally-measured densities. ${ }^{6}$ At a fixed temperature of $303 \mathrm{~K}$, the mole fraction of $\mathrm{LiTf}_{2} \mathrm{~N}$ in the VIm monomers was varied from a value of approximately 0.09 to a value of 0.25 , with the density comparison shown in Figure 5. The simulated densities are consistently higher than the experimental values by approximately $5 \%$, but this is an improvement over the results obtained using the original intermolecular parameters for $\operatorname{LiTf}_{2} \mathrm{~N}$, which led to discrepancies of close to $10 \%$ (data not shown). In lieu of any other experimental benchmarks for this mixture, we were not motivated to pursue any further parameter alteration, as this error falls within the level of accuracy that one might expect using purely predictive methods of force field generation. ${ }^{53}$ This issue may be revisited in the future, as additional experimental data would allow for further quantitative improvement. 


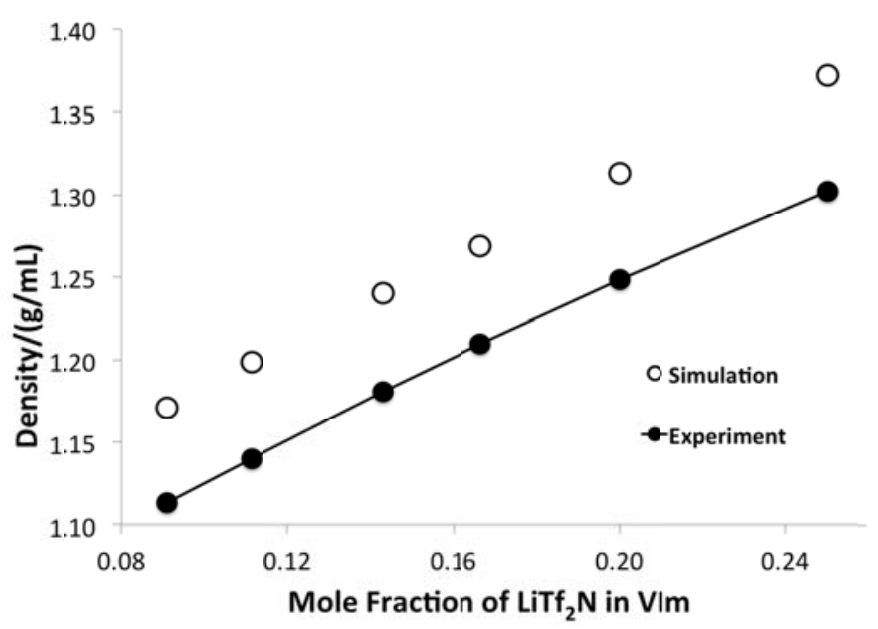

Figure 5. Gravimetric density values with respect to mole fraction of $\operatorname{LiTf}_{2} \mathrm{~N}$ in VIm at a temperature of $303 \mathrm{~K}$.

\subsection{Pre-Polymerization Molecular Structure}

Following the initial experimental benchmarking of the simulation models, sitesite radial distribution functions were calculated to explore the coordination of the molecules in the system. For this study, the two most important pair interactions are: (a) the correlation between the carbons on the alkene functional group where polymerization takes place (C8 and C9 sites); and (b) the interactions between $\mathrm{Li}^{+}$and the NB nitrogen on the exterior region of the imidazole ring in VIm. In experiments, the addition of $\mathrm{LiTf}_{2} \mathrm{~N}$ raised both reaction rate and conversion. ${ }^{6}$ In our simulations, we find that as the concentration of $\operatorname{LiTf}_{2} \mathrm{~N}$ in the VIm mixture is increased (up to a mole fraction of 0.50 ), there is a higher probability of finding the polymerizing carbons (C8 and C9) in neighboring molecules in close proximity. This is similar to the structural changes found in other simulation studies, as well. ${ }^{31}$ When comparing the pure VIm monomers to the solution with $50 \mathrm{~mol} \% \mathrm{LiTf}_{2} \mathrm{~N}$, the height of the first peak in Figure 6 shifts from approximately 1.17 to a value of 1.52, indicating a significant enrichment in the local C8C9 coordination. 


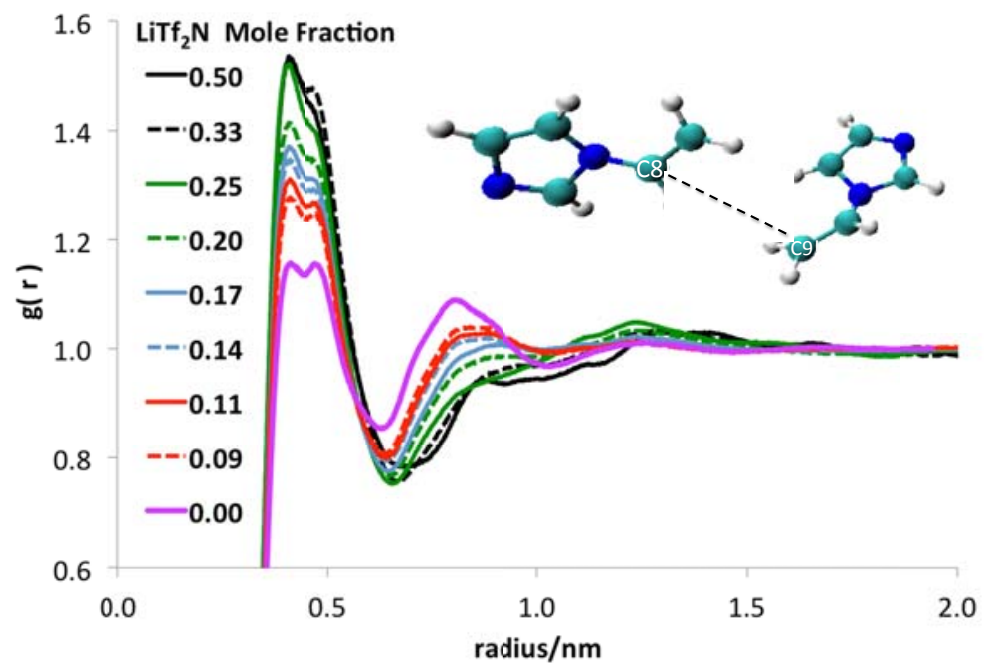

Figure 6. Comparison of radial distribution functions of systems with varying mole fractions of $\mathrm{LiTf}_{2} \mathrm{~N}$ in VIm. The site-site radial distribution function is defined between the C8 and C9 carbons on the alkene group of VIm.

To further explore the direct effect of the $\operatorname{LiTf}_{2} \mathrm{~N}$ on the pre-polymerization structure of the VIm monomers, we analyzed the local coordination of the VIm molecules around the $\mathrm{Li}^{+}$cations. To determine a reasonable cut off for this calculation (i.e., the extent of first coordination shell), a radial distribution function of the $\mathrm{Li}^{+}$and $\mathrm{NB}$ sites (shown in Figure 1) was calculated, and Figure 7 illustrates that a cutoff distance of 0.3 $\mathrm{nm}$ is a reasonable estimate of the coordination shell.

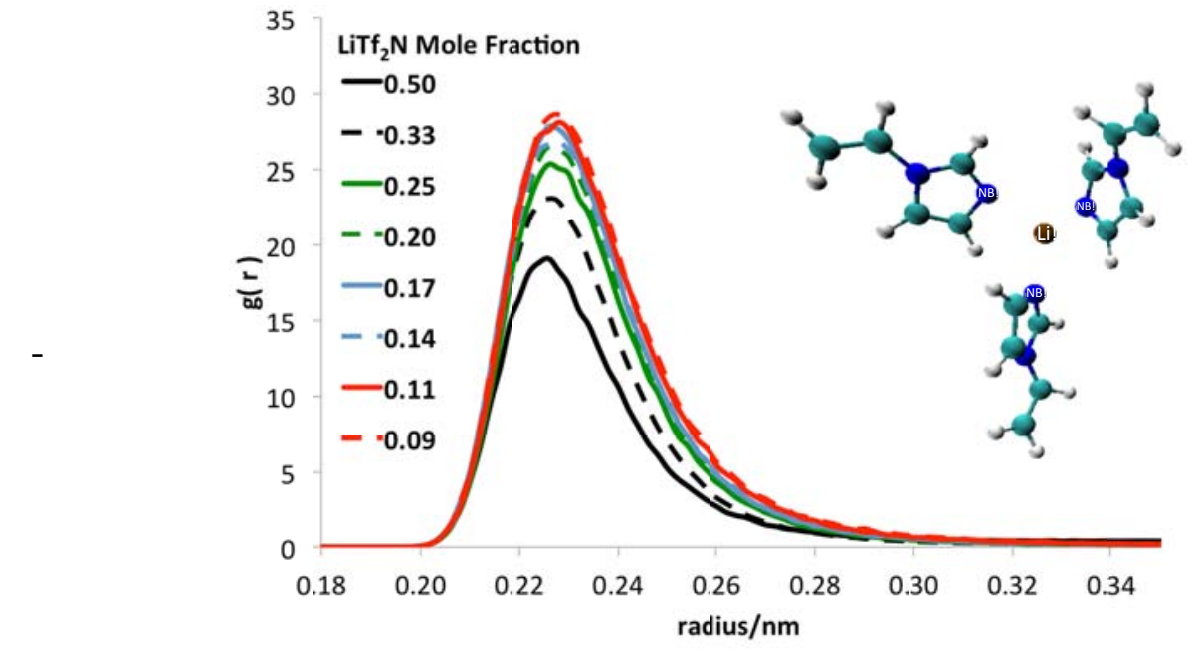

Figure 7. Radial distribution function of $\mathrm{Li}^{+}-\mathrm{NB}$ at different mole fractions of $\operatorname{LiTf}_{2} \mathrm{~N}$ in VIm at a temperature of $303 \mathrm{~K}$. 
The coordination of VIm about the $\mathrm{Li}^{+}$cations was calculated for all concentrations of $\operatorname{LiTf}_{2} \mathrm{~N}$ in VIm. This local coordination environment was then compared to infrared spectroscopy absorbance data taken from experimental samples of these same solutions. Figure 8 shows the overlay of the experimental spectroscopy data and the simulated predictions of the local $\mathrm{Li}^{+}$coordination environment. While there is not a quantitative correlation between these two separate sources of data, the experimental and computational perspectives tend to mimic the same trend, especially when examining the 1:1 and 2:1 interactions. Thus, one might infer that the interaction measured through IR spectroscopy is reflecting the local coordination of the VIm and $\mathrm{Li}^{+}$ interaction. While this observation is not conclusive, it can be more rigorously explored in future studies of similar systems.

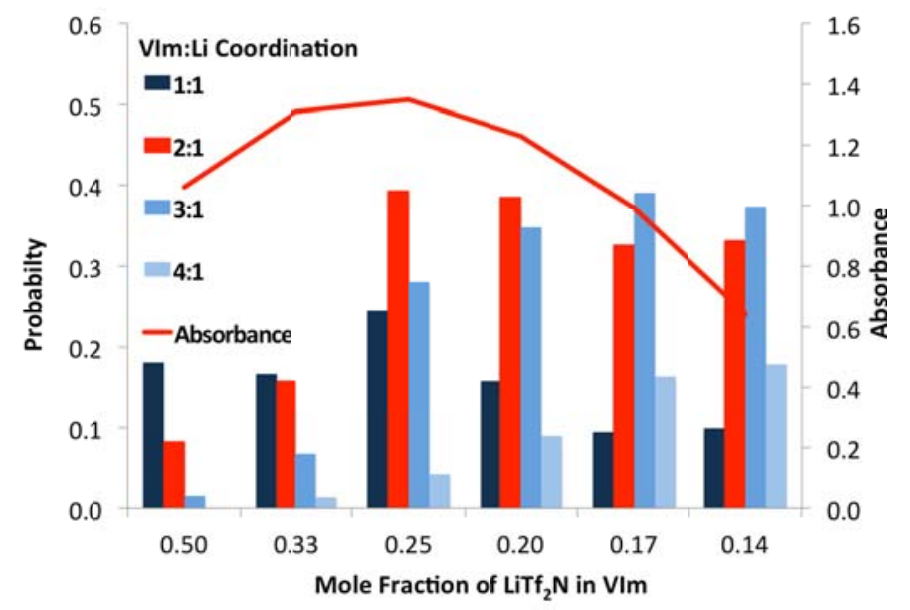

Figure 8. Comparison of coordination of VIm about the $\mathrm{Li}^{+}$cation of solutions with different mole fractions of $\mathrm{LiTf}_{2} \mathrm{~N}$ at $303 \mathrm{~K}$. The plot above shows that for the simulated coordination data is consistent with the trends of the experimental absorbance data.

\subsection{Diffusion Coefficients}

Our molecular dynamics simulations indicate that the equilibrium molecular arrangement of the VIm monomers is altered by the $\operatorname{LiTf}_{2} \mathrm{~N}$ addition, but there may also 
be changes to the molecular kinetics that enhance the polymerization behavior. In order to gather some direct information about the system transport properties, the self-diffusion coefficients of the VIm monomers, $\mathrm{Li}^{+}$, and $\mathrm{Tf}_{2} \mathrm{~N}^{-}$were estimated within each of the $\operatorname{LiTf}_{2} \mathrm{~N}+\mathrm{VIm}$ mixtures. The self-diffusion coefficients were calculated with the g_velacc analysis script within Gromacs, which calculates the diffusion coefficient based on the integrating the velocity autocorrelation function (VACF) during the simulations. After initial equilibration, results from four different $10 \mathrm{~ns}$ trajectories were averaged (for a total of $40 \mathrm{~ns}$ of production time), so that accurate system averages and standard deviations could be calculated. Surprisingly, there was very little change in the selfdiffusion coefficients with respect to the composition of the mixture, as shown in Figure 9. There is a slight increase in the magnitude of the diffusion coefficient of VIm and $\mathrm{Tf}_{2} \mathrm{~N}^{-}$as the $\mathrm{LiTf}_{2} \mathrm{~N}$ concentration increases, but with only a 2-3\% difference between highest and lowest values computed, the impact is only marginally greater than the error bars of the data. Although this is not a comprehensive evaluation of the dynamic properties of the system, the simulation results do not indicate that increased polymerization rates would be attributed to an IL-induced acceleration of the system kinetics. Thus, the most likely explanation for the experimentally-observed polymerization behavior still seems to be associated with the specific pre-polymerization molecular structures that are induced by the IL addition. 


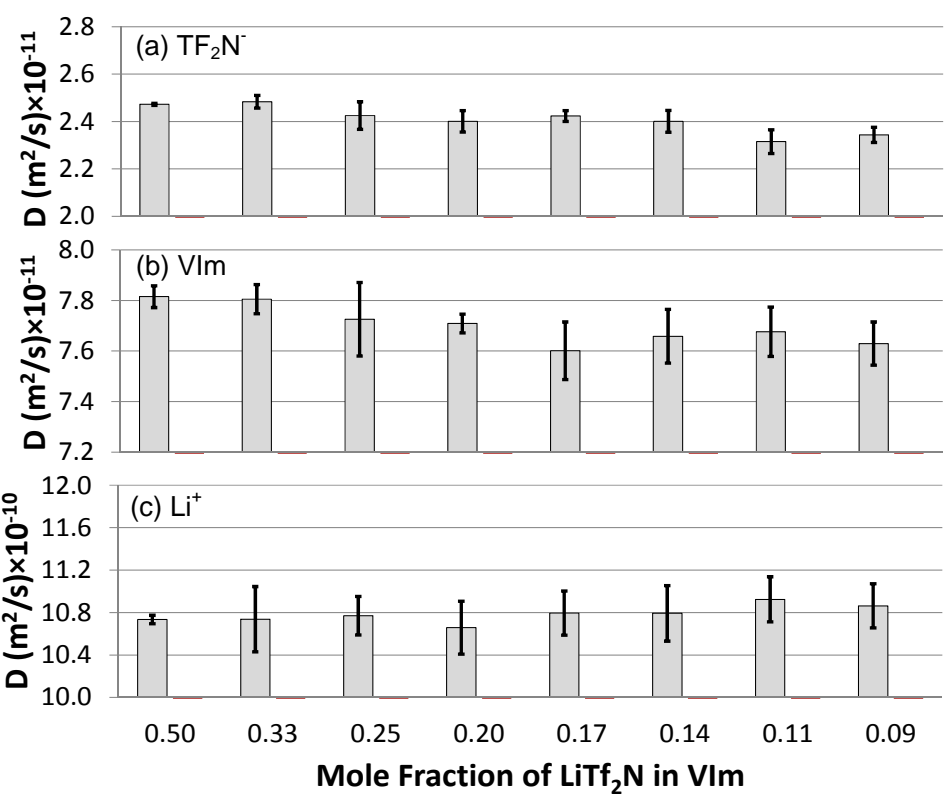

Figure 9. Self-diffusion coefficients of the individual components in different $\operatorname{LiTf}_{2} \mathrm{~N}+\mathrm{VIm}$ mixtures at a temperature of $303 \mathrm{~K}$ and a pressure of 1 bar. The error bars indicate the standard deviation calculated from four different independent 10 ns time blocks.

A common property of ionic liquids is the tendency to segregate and cluster at nanometer length scales. In the present case, with the addition of a second compound, there is the possibility to segregate into VIm-rich and IL-rich domains. This phenomenon is another factor that could influence the experimentally-observed polymerization behavior, and it is possible to quantify this behavior by further analyzing the molecular dynamics simulation trajectories. Following the work of Siepmann and co-workers, ${ }^{55}$ we have generated plots of the local mole fraction enhancement to quantify the presence of clustering in our fluid mixtures. The local mole fraction of $\operatorname{VIm}\left(\mathrm{x}_{\mathrm{VIm}}(\mathrm{r})\right)$ relative to the bulk value $\left(\mathrm{X}_{\mathrm{VIm}}(\mathrm{bulk})\right)$ is plotted as a function of the radial distance from the molecule center. Thus, values above 1.0 indicate that there is a tendency for the VIm molecules to form clusters. The results over a range of different IL:VIm concentrations are illustrated in Figure 10. In general, there is only a very slight deviation from a value of 1.0, and 
even at the highest concentration of $\operatorname{LiTf}_{2} \mathrm{~N}$, the tendency of the VIm molecules to cluster appears to be negligible. In comparison to the other structural analyses performed, the shift in the specific site-site coordination of the neighboring molecules still emerges as the dominant influence of the IL addition.

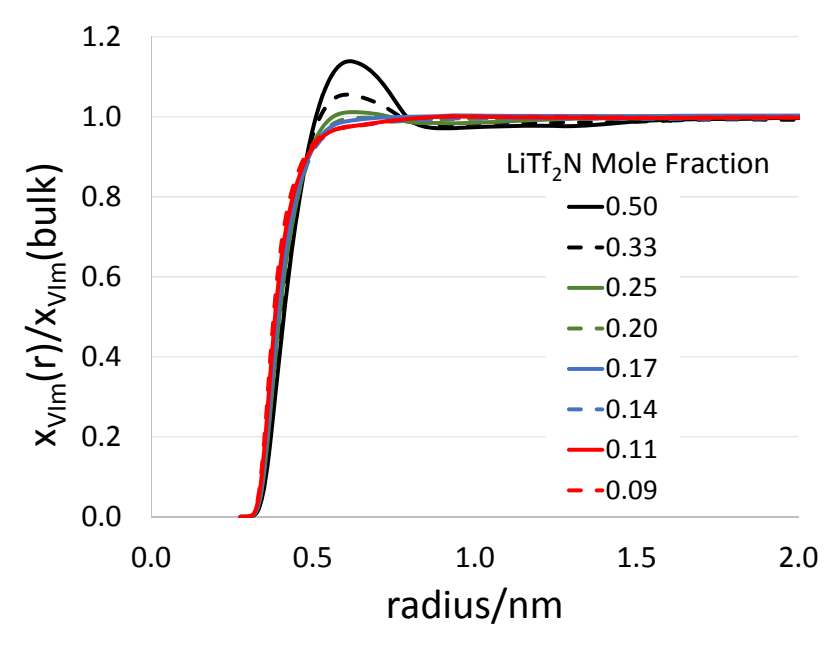

Figure 10. Local mole fraction enhancement of the VIm molecule around itself at different concentrations of $\operatorname{LiTf}_{2} \mathrm{~N}$, corresponding to a temperature of $303 \mathrm{~K}$ and a pressure of $1 \mathrm{bar}$.

\subsection{Comparison with Other Ionic Liquids: $\mathrm{NaTf}_{2} \mathrm{~N}, \mathrm{LiPF}_{6}$, and $\mathrm{LiBF}_{4}$}

In order to broaden our investigation and explore the role of other bulky metal salts on the VIm pre-polymerization structure, three other similar salts were considered: $\mathrm{NaTf}_{2} \mathrm{~N}, \mathrm{LiPF}_{6}$, and $\mathrm{LiBF}_{4}$. Since experimental data was available in literature, ${ }^{50}$ the simulated densities of pure $\mathrm{NaTf}_{2} \mathrm{~N}$ were compared to experimental data before analyzing the coordination effects. For consistency, the same LJ scaling procedure for $\operatorname{LiTf}_{2} \mathrm{~N}$ was used to modify the original $\mathrm{NaTf}_{2} \mathrm{~N}$ model (i.e. scaling all the sigma values by 1.05), and the resulting parameters are listed in Table 2. The LJ parameters for $\mathrm{LiPF}_{6}$ and $\mathrm{LiBF}_{4}$ were not modified from the original source ${ }^{49}$ as they were derived for a eutectic mixture similar to the one used in this work. The simulated densities of $\mathrm{NaTf}_{2} \mathrm{~N}$ were found to 
fall within 2-3\% of the experimental densities (shown in Figure 11), ${ }^{50}$ which was deemed acceptable. $^{53}$

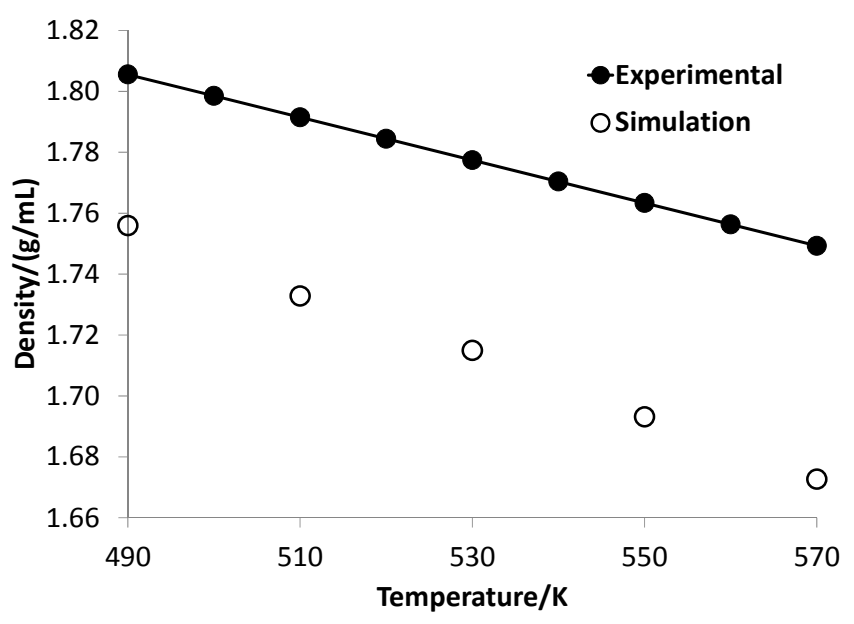

Figure 11. Density of pure $\mathrm{NaTf}_{2} \mathrm{~N}$ with respect to temperature, calculated using the scaled $\mathrm{LJ}$ potentials shown in Table 2, along with experimentally-measured densities taken from the literature. $^{50}$

Once again, the radial distribution functions show how VIm coordinates in a mixture with $\mathrm{NaTf}_{2} \mathrm{~N}$. Similar to $\mathrm{LiTf}_{2} \mathrm{~N}$, as the concentration of $\mathrm{NaTf}_{2} \mathrm{~N}$ increases, the magnitude of the g(r) function also increases, meaning the local concentration of the C8 and C9 VIm atoms is also increased. Figure 12 directly compares the 3:1 VIm to IL mixtures of both $\mathrm{LiTf}_{2} \mathrm{~N}$ and $\mathrm{NaTf}_{2} \mathrm{~N}$, illustrating that there is a slightly higher local concentration of VIm in the solution containing $\operatorname{LiTf}_{2} \mathrm{~N}$. One possible reason for this behavior is shown in Figure 13, a radial distribution function of the $\mathrm{Na}^{+}-\mathrm{NB}$ sites. The peak between $\mathrm{Na}^{+}$and NB occurs at a longer distance than between $\mathrm{Li}^{+}$and NB. This is likely due to the larger size of the $\mathrm{Na}^{+}$cation. As observed with the $\mathrm{Li}^{+}$cation, VIm also forms a complex with the $\mathrm{Na}^{+}$cation, but the characteristics are somewhat different. Coordination calculations (Figure 14, this time using a cut-off of $0.4 \mathrm{~nm}$ ) show that VIm has a higher coordination about $\mathrm{Na}^{+}$than it does with $\mathrm{Li}^{+}$. Once again, this may be due to 
the fact that $\mathrm{Na}^{+}$is a larger atom and therefore has more surface area for coordinating monomers.

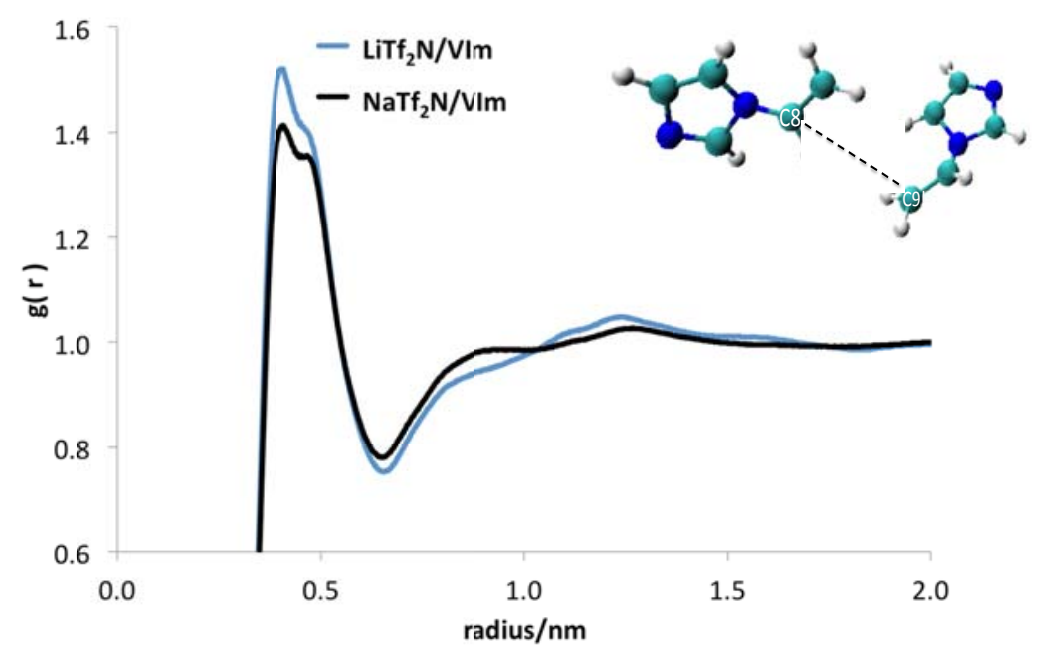

Figure 12. Radial distribution function of C8-C9 atoms of VIm for the 3:1 VIm to IL solutions at a temperature of $303 \mathrm{~K}$. The graph shows that mixtures containing $\mathrm{Li}^{+}$have a stronger probability of favorable conformations.

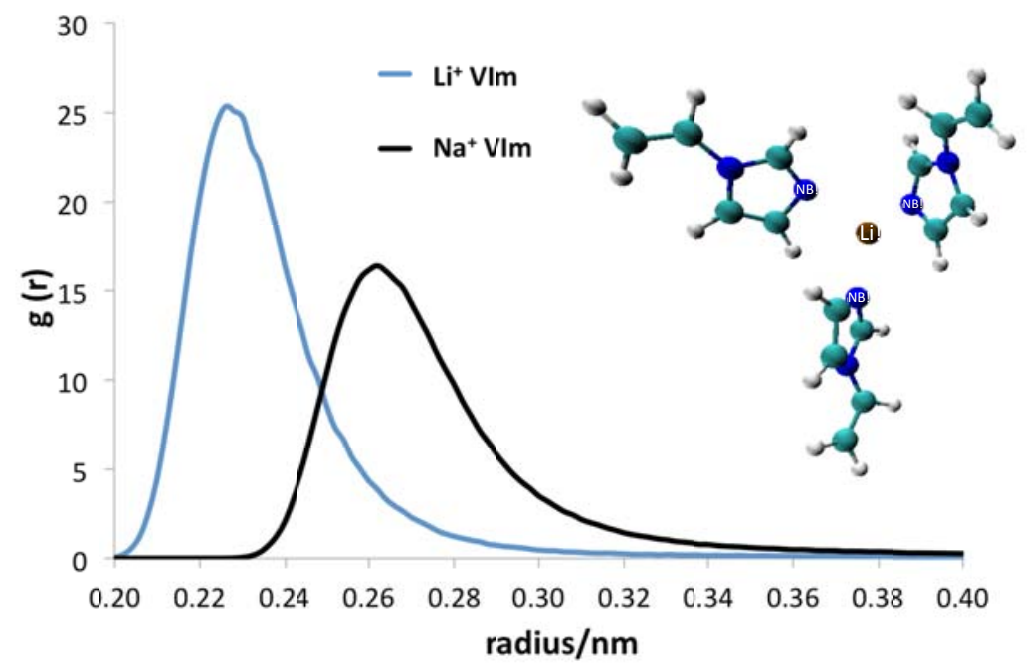

Figure 13. A radial distribution function of the cation and NB atom of VIm for the 3:1 VIm to IL solutions at a temperature of $303 \mathrm{~K}$. The graph shows that mixtures containing $\mathrm{Li}^{+}$have a closer interaction with the VIm monomers than $\mathrm{Na}^{+}$. 


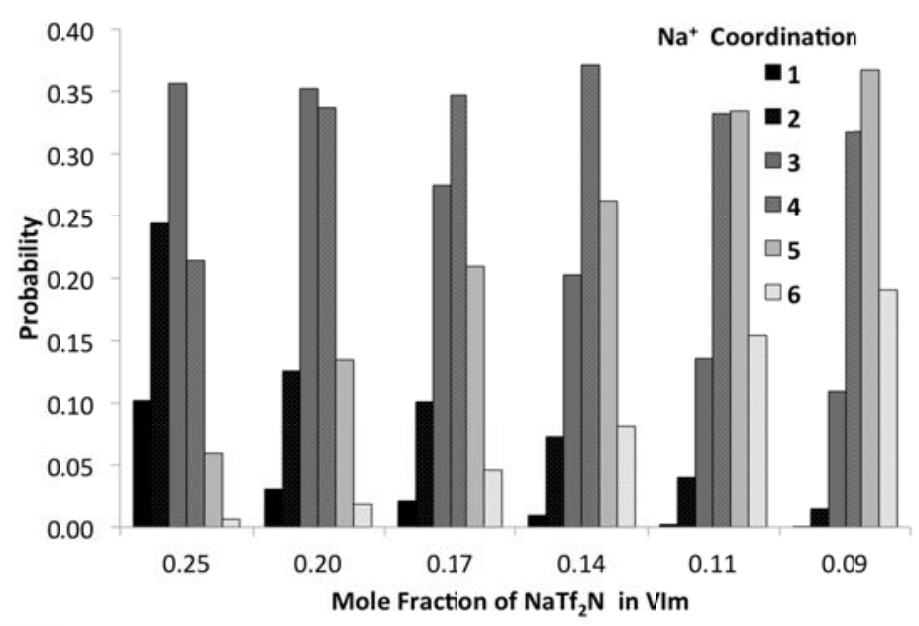

Figure 14. Comparison of the average number of VIm molecules about the $\mathrm{Na}^{+}$atom with different mole fractions of $\mathrm{NaTf}_{2} \mathrm{~N}$ at $303 \mathrm{~K}$.

To explore any effects that the anion might have on the system, two other anions of different size were tested in the same manner as above and used for comparison. The anions, $\mathrm{PF}_{6}^{-}$and $\mathrm{BF}_{4}^{-}$were chosen because they were smaller than $\mathrm{Tf}_{2} \mathrm{~N}^{-}$and they have a high fluorine content, similar to $\mathrm{Tf}_{2} \mathrm{~N}^{-}$. Using the same radial distribution function analysis, Figure 15 suggests that while the addition of $\mathrm{LiPF}_{6}$ or $\mathrm{LiBF}_{4}$ enhances the coordination relative to the pure VIm solution, the probability of finding C8 and C9 in close proximity is still less than that of the VIm $+\operatorname{LiTf}_{2} \mathrm{~N}$ mixture. This data shows that there is some correlation between the selected anion and the local concentration of VIm, which is suggested to affect the polymerization behavior of VIm. 


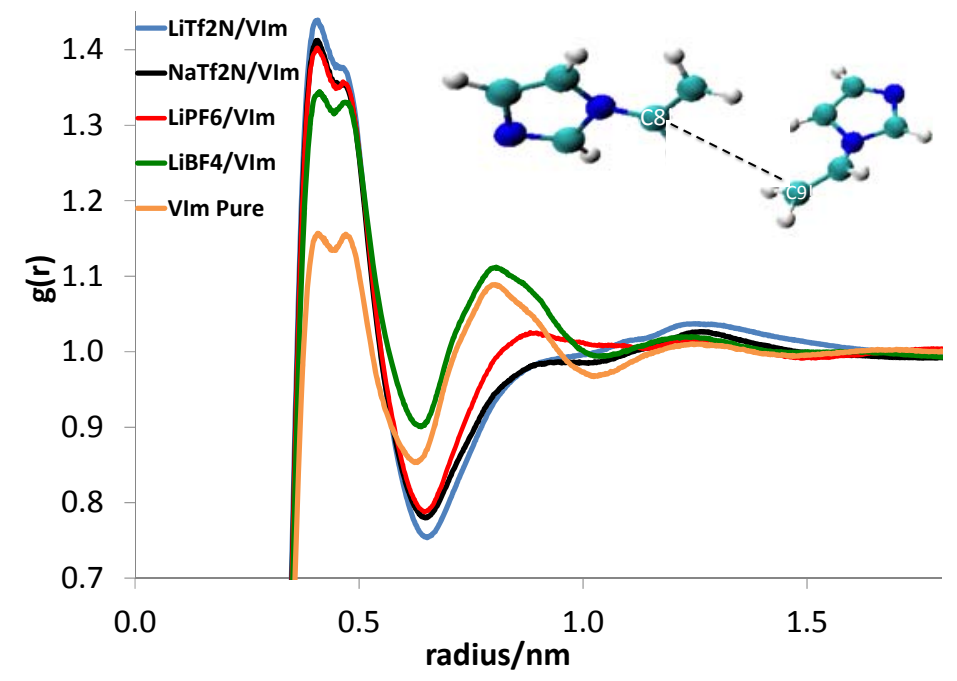

Figure 15. Comparison of radial distribution functions of the C8 and C9 atom of VIm. All mixed solutions have a ratio of 3:1 VIm to IL and are at $303 \mathrm{~K}$.

To further assess the molecular structure in solution, another coordination analysis of VIm about $\mathrm{Li}^{+}$was conducted for the mixtures containing $\mathrm{PF}_{6}{ }^{-}$and $\mathrm{BF}_{4}{ }^{-}$ anions. The results of this calculation, shown graphically in Figure 16, indicate that unlike the solutions with $\operatorname{LiTf}_{2} \mathrm{~N}$, which seem to prefer a coordination of two or three VIm molecules, the VIm monomers in $\mathrm{LiPF}_{6}$ and $\mathrm{LiBF}_{4}$ mixtures appear to have a higher probability of being in a 1:1 ratio of coordination with the $\mathrm{Li}^{+}$cation or not coordinated at all. The driving force for this could be that $\mathrm{PF}_{6}{ }^{-}$and $\mathrm{BF}_{4}{ }^{-}$are more strongly coordinated with $\mathrm{Li}^{+}$, thus hindering the interaction between $\mathrm{Li}^{+}$and $\mathrm{VIm}$. 


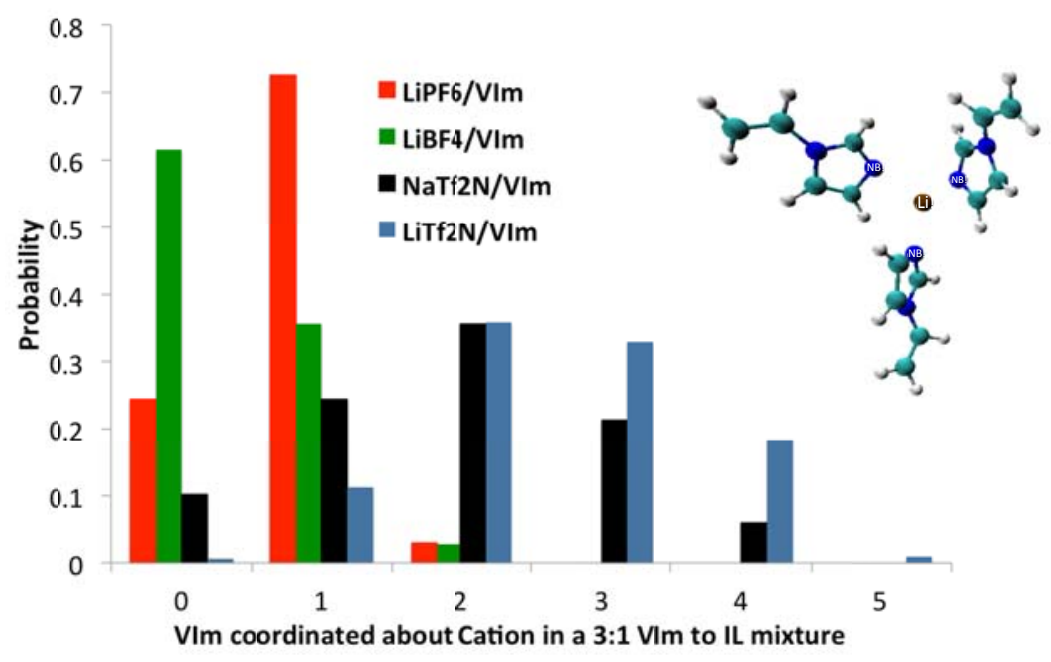

Figure 16. Coordination of VIm to cation probabilities of solutions with different ILs. All solutions in this comparison are at 303K and have a VIm to IL ratio of 3:1.

\section{Conclusions}

We offer a molecular-level analysis as to why the addition of a metal salts with bulky, weakly coordinating molecular anions significantly increases the polymerization rate and conversion of VIm. Our results show that there are specific interactions between the metal cations and VIm, resulting in a structured media that does not experience the typical limitations associated with photopolymerization. Although we cannot directly probe the polymerization process in the MD simulations, the data from the VIm monomer solutions highlights the potential role of the pre-polymerization fluid structures.

There is an apparent relationship between the probability of 2:1 VIm-cation interactions and the local concentration of VIm. Although a 2:1 ratio of VIm about the cation seems to aid in the pre-polymerization coordination, the presence of higher ratios might inhibit this favorable coordination. The graphs also distinctly show that as the concentration of salt increases up to $50 \mathrm{~mol} \%$, the local concentration of the vinyl groups increase, directly linking this data to experimental findings and overcoming the mass transport limitation in radical photopolymerization. In comparison with $\mathrm{LiPF}_{6}$ and $\mathrm{LiBF}_{4}$, 
mixtures containing $\operatorname{LiTf}_{2} \mathrm{~N}$ were found to have a higher probability of monomers in a favorable coordination for polymerization. It is suggested that because $\mathrm{Tf}_{2} \mathrm{~N}^{-}$is a larger molecule, it has a weaker association with its cation than the smaller $\mathrm{PF}_{6}{ }^{-}$and $\mathrm{BF}_{4}{ }^{-}$ molecules, allowing VIm to more easily cluster around the $\mathrm{Li}^{+}$cation. Another possible explanation for the differences relates to the ability of $\mathrm{Tf}_{2} \mathrm{~N}^{-}$anions to self-orient in polar and nonpolar regions.

Changing the cation of the IL also had an influence over the coordination and local concentration. Despite the higher order of coordination that occurs in mixtures with $\mathrm{Na}^{+}$, VIm interacts with the cation in a similar manner as it does with $\mathrm{Li}^{+}$. This is most likely why there is only a slight shift in both radial distribution functions and coordination data.

Based on the results shown in this work, it is likely that the addition of other metal $\mathrm{Tf}_{2} \mathrm{~N}$ salts may yield even higher local concentrations of the polymerizing atoms of VIm, and this should motivate additional computational and experimental studies of similar systems in the future. Also, the role of the transport properties deserves further attention, especially the changes encountered during the course of the polymerization reactions.

\section{ACKNOWLEDGEMENTS}

Financial support was provided by the National Science Foundation (CBET-1159397 and EEC-1358750). 


\section{References:}

1. Yildiz, G.; Oztekin, N.; Orbay, A.; Senkal, F. Voltammetric determination of nitrite in meat products using polyvinylimidazole modified carbon paste electrode. Food Chemistry 2014, 152, 245-250.

2. $\quad$ MacAodha, D.; Conghaile, P. O.; Egan, B.; Kavanagh, P.; Leech, D.

Membraneless Glucose/Oxygen Enzymatic Fuel Cells Using Redox Hydrogel Films Containing Carbon Nanotubes. ChemPhysChem 2013, 14 (10), 2302-2307.

3. Farjaminezhad, M.; Tehrani, M. S.; Azar, P. A.; Hussain, S. W.; Bohlooli, S. Polyvinylimidazole/sol-gel composite as a novel solid-phase microextraction coating for the determination of halogenated benzenes from aqueous solutions. Journal of Separation Science 2014, 37 (12), 1475-1481.

4. Corazza, M. Z.; Ribeiro, E. S.; Segatelli, M. G.; Tarley, C. R. T. Study of crosslinked poly(methacrylic acid) and polyvinylimidazole as selective adsorbents for on-line preconcentration and redox speciation of chromium with flame atomic absorption spectrometry determination. Microchemical Journal 2014, 117, 18-26.

5. Wang, R. X.; Men, J. Y.; Gao, B. J. The Adsorption Behavior of Functional Particles Modified by Polyvinylimidazole for Cu(II) Ion. Clean-Soil Air Water 2012, 40 (3), 278-284.

6. Whitley, J. W.; Home, W. J.; Danielsen, S. P. O.; Shannon, M. S.; Marshall, J. E.; Hayward, S. H.; Gaddis, C. J.; Bara, J. E. Enhanced photopolymerization rate \& conversion of 1-vinylimidazole in the presence of lithium bistriflimide. European Polymer Journal 2014, 60, 92-97.

7. Tajima, K.; Aida, T. Controlled polymerizations with constrained geometries. Chem. Commun. (Cambridge) 2000, (24), 2399-2412.

8. $\quad$ O'Brien, D. F.; Armitage, B.; Benedicto, A.; Bennett, D. E.; Lamparski, H. G.; Lee, Y.-S.; Srisiri, W.; Sisson, T. M. Polymerization of Preformed Self-Organized Assemblies. Acc. Chem. Res. 1998, 31 (12), 861-868.

9. Gin, D. L.; Gu, W.; Pindzola, B. A.; Zhou, W.-J. Polymerized Lyotropic Liquid Crystal Assemblies for Materials Applications. Acc. Chem. Res. 2001, 34 (12), 973-980.

10. Matsumoto, A.; Yokoi, K. Control of molecular weight of the polymers produced during the crystalline-state photopolymerization of diethyl cis,cis-muconate as studied by gel permeation chromatography and scanning electron micrography. J. Polym. Sci., Part A: Polym. Chem. 1998, 36 (17), 3147-3155.

11. Matsumoto, A.; Yokoi, K.; Aoki, S.; Tashiro, K.; Kamae, T.; Kobayashi, M. Crystalline-State Polymerization of Diethyl (Z,Z)-2,4-Hexadienedioate via a Radical 
Chain Reaction Mechanism To Yield an Ultrahigh-Molecular-Weight and Stereoregular Polymer. Macromolecules 1998, 31 (7), 2129-2136.

12. Guymon, C. A.; Bowman, C. N. Kinetic Analysis of Polymerization Rate Acceleration During the Formation of Polymer/Smectic Liquid Crystal Composites. Macromolecules 1997, 30 (18), 5271-5278.

13. Lester, C. L.; Guymon, C. A. Ordering effects on the photopolymerization of a lyotropic liquid crystal. Polymer 2002, 43 (13), 3707-3715.

14. Lester, C. L.; Guymon, C. A. Phase behavior and polymerization kinetics of a semifluorinated lyotropic liquid crystal. Macromolecules 2000, 33 (15), 5448-5454.

15. Lester, C. L.; Colson, C. D.; Guymon, C. A. Photopolymerization Kinetics and Structure Development of Templated Lyotropic Liquid Crystalline Systems. Macromolecules 2001, 34 (13), 4430-4438.

16. Han, X.; Armstrong, D. W. Ionic liquids in separations. Accounts of Chemical Research 2007, 40 (11), 1079-1086.

17. Bara, J. E.; Camper, D. E.; Gin, D. L.; Noble, R. D. Room-Temperature Ionic Liquids and Composite Materials: Platform Technologies for CO2 Capture. Acc. Chem. Res. 2010, 43 (1), 152-159.

18. Earle, M. J.; Esperanca, J. M. S. S.; Gilea, M. A.; Canongia, L. J. N.; Rebelo, L. P. N.; Magee, J. W.; Seddon, K. R.; Widegren, J. A. The distillation and volatility of ionic liquids. Nature 2006, 439 (7078), 831-834.

19. Canongia, L. J. N. A.; Padua, A. A. H. Nanostructural Organization in Ionic Liquids. J. Phys. Chem. B 2006, 110 (7), 3330-3335.

20. Russina, O.; Triolo, A. New experimental evidence supporting the mesoscopic segregation model in room temperature ionic liquids. Faraday Discuss. 2012, 154 (Ionic Liquids), 97-109.

21. Hallett, J. P.; Welton, T. Room-temperature ionic liquids: Solvents for synthesis and catalysis. 2. Chem. Rev. 2011, 111 (5), 3508-3576.

22. Kubisa, P. Ionic liquids as solvents for polymerization processes-Progress and challenges. Prog. Polym. Sci. 2009, 34 (12), 1333-1347.

23. Hong, K.; Zhang, H.; Mays, J. W.; Visser, A. E.; Brazel, C. S.; Holbrey, J. D.; Reichert, W. M.; Rogers, R. D. Conventional free radical polymerization in room temperature ionic liquids: a green approach to commodity polymers with practical advantages. Chem. Commun. 2002, (13), 1368-1369. 
24. Harrisson, S.; Mackenzie, S. R.; Haddleton, D. M. Unprecedented solventinduced acceleration of free-radical propagation of methyl methacrylate in ionic liquids. Chem. Commun. 2002, (23), 2850-2851.

25. Schmidt-Naake, G.; Woecht, I.; Schmalfuss, A. Ionic liquids - new solvents in the free radical polymerization. Macromol. Symp. 2007, 259, 226-235.

26. Woecht, I.; Schmidt-Naake, G.; Beuermann, S.; Buback, M.; Garcia, N. Propagation kinetics of free-radical polymerizations in ionic liquids. J. Polym. Sci., Part A: Polym. Chem. 2008, 46 (4), 1460-1469.

27. Matsumoto, A.; Nakamura, S. Radical polymerization of methyl methacrylate in the presence of magnesium bromide as the Lewis acid. Journal of Applied Polymer Science 1999, 74 (2), 290-296.

28. Bamford, C. H.; Jenkins, A. D.; Johnston, R. Studies in polymerization. 12. Salt effects on the polymerization of acrylonitrile in non-aqueous solution. Proceedings of the Royal Society of London Series A-Mathematical and Physical Sciences 1957, 241 (1226), 364-375.

29. Tazuke, S.; Okamura, S. Effects of metal salts on polymerization. 6. Photo and thermally catalyzed polymerization of N-vinylimidazole in presence of metal salts. Journal of Polymer Science Part a-1-Polymer Chemistry 1969, 7 (3PA1), 851-\&.

30. Noble, B. B.; Smith, L. M.; Coote, M. L. The effect of $\operatorname{LiNTf}_{2}$ on the propagation rate coefficient of methyl methacrylate. Polymer Chemistry 2014, 5 (17), 4974-4983.

31. Li, Z.; Smith, G. D.; Bedrov, D. Li+ Salvation and Transport Properties in Ionic Liquid/Lithium Salt Mixtures: A Molecular Dynamics Simulation Study. Journal of Physical Chemistry B 2012, 116 (42), 12801-12809.

32. Haskins, J. B.; Bennett, W. R.; Wu, J. J.; Hernandez, D. M.; Borodin, O.; Monk, J. D.; Bauschlicher, C. W.; Lawson, J. W. Computational and Experimental Investigation of Li-Doped Ionic Liquid Electrolytes: pyr14 TFSI , pyr13 FSI , and EMIM BF 4 . Journal of Physical Chemistry B 2014, 118 (38), 11295-11309.

33. Hayamizu, K.; Tsuzuki, S.; Seki, S.; Fujii, K.; Suenaga, M.; Umebayashi, Y. Studies on the translational and rotational motions of ionic liquids composed of Nmethyl-N-propyl-pyrrolidinium (P-13) cation and bis(trifluoromethanesulfonyl)amide and bis(fluorosulfonyl)amide anions and their binary systems including lithium salts. Journal of Chemical Physics 2010, 133 (19).

34. Hess, B.; Kutzner, C.; van der Spoel, D.; Lindahl, E. GROMACS 4: Algorithms for highly efficient, load-balanced, and scalable molecular simulation. Journal of Chemical Theory and Computation 2008, 4 (3), 435-447.

35. Parrinello, M.; Rahman, A. crystal-structure and pair potentials - a moleculardynamics study. Physical Review Letters 1980, 45 (14), 1196-1199. 
36. Hoover, W. G. Canonical dynamics o equilibrium phase-space distributions. Physical Review A 1985, 31 (3), 1695-1697.

37. Essmann, U.; Perera, L.; Berkowitz, M. L.; Darden, T.; Lee, H.; Pedersen, L. G. A smooth particle mesh Ewald method. Journal of Chemical Physics 1995, 103 (19), 85778593.

38. Allen, M. P.; Tildesley, D. J. Computer Simulation of Liquids. Oxford University Press: Oxford, UK, 1989.

39. Jorgensen, W. L.; Maxwell, D. S.; TiradoRives, J. Development and testing of the OPLS all-atom force field on conformational energetics and properties of organic liquids. Journal of the American Chemical Society 1996, 118 (45), 11225-11236.

40. Lopes, J. N. C.; Padua, A. A. H. Molecular force field for ionic liquids composed of triflate or bistriflylimide anions. Journal of Physical Chemistry B 2004, 108 (43), 16893-16898; Carignano, M. A. Structure and Dynamics of PF6 P-1,P-2,P-2,P-4 from Molecular Dynamics Simulations. Journal of Physical Chemistry B 2013, 117 (48), 15176-15183.

41. Shim, Y.; Choi, M. Y.; Kim, H. J. A molecular dynamics computer simulation study of room-temperature ionic liquids. II. Equilibrium and nonequilibriurn solvation dynamics. Journal of Chemical Physics 2005, 122 (4), 12.

42. Frisch, M. J.; Trucks, G. W.; Schlegel, H. B.; Scuseria, G. E.; Robb, M. A.; Cheeseman, J. R.; Scalmani, G.; Barone, V.; Mennucci, B.; Petersson, G. A.; Nakatsuji, H.; Caricato, M.; Li, X.; Hratchian, H. P.; Izmaylov, A. F.; Bloino, J.; Zheng, G.; Sonnenberg, J. L.; Hada, M.; Ehara, M.; Toyota, K.; Fukuda, R.; Hasegawa, J.; Ishida, M.; Nakajima, T.; Honda, Y.; Kitao, O.; Nakai, H.; Vreven, T.; Montgomery, J. A., Jr.; Peralta, J. E.; Ogliaro, F.; Bearpark, M.; Heyd, J. J.; Brothers, E.; Kudin, K. N.; Staroverov, V. N.; Kobayashi, R.; Normand, J.; Raghavachari, K.; Rendell, A.; Burant, J. C.; Iyengar, S. S.; Tomasi, J.; Cossi, M.; Rega, N.; Millam, M. J.; Klene, M.; Knox, J. E.; Cross, J. B.; Bakken, V.; Adamo, C.; Jaramillo, J.; Gomperts, R.; Stratmann, R. E.; Yazyev, O.; Austin, A. J.; Cammi, R.; Pomelli, C.; Ochterski, J. W.; Martin, R. L.; Morokuma, K.; Zakrzewski, V. G.; Voth, G. A.; Salvador, P.; Dannenberg, J. J.; Dapprich, S.; Daniels, A. D.; Farkas, Ö.; Foresman, J. B.; Ortiz, J. V.; Cioslowski, J.; Fox, D. J. Gaussian 09. Gaussian, Inc.: Wallingford CT, 2009.

43. Becke, A. D. Density-functional thermochemistry. III. The role of exact exchange. J. Chem. Phys. 1993, 98.

44. Reed, A. E.; Curtiss, L. A.; Weinhold, F. Intermolecular interactions from a natural bond orbital, donor-acceptor viewpoint. Chemical Reviews 1988, 88 (6), 899-926.

45. Liu, H. N.; Bara, J. E.; Turner, C. H. DFT study on the effect of exocyclic substituents on the proton affinity of 1-methylimidazole. Chemical Physics 2013, 416, 21-25. 
46. Chaban, V. V.; Voroshylova, I. V. Systematic Refinement of Canongia LopesPadua Force Field for Pyrrolidinium-Based Ionic Liquids. Journal of Physical Chemistry B 2015, 119 (20), 6242-6249.

47. Zhang, Y.; Maginn, E. J. A Simple AIMD Approach to Derive Atomic Charges for Condensed Phase Simulation of Ionic Liquids. Journal of Physical Chemistry B 2012, 116 (33), 10036-10048.

48. Zhao, W.; Eslami, H.; Cavalcanti, W. L.; Mueller-Plathe, F. A refined all-atom model for the ionic liquid 1-n-butyl 3-methylimidazolium bis(trifluoromethylsulfonyl)imide bmim Tf2N. Zeitschrift Fur Physikalische ChemieInternational Journal of Research in Physical Chemistry \& Chemical Physics 2007, 221 (11-12), 1647-1662.

49. Mendez-Morales, T.; Carrete, J.; Bouzon-Capelo, S.; Perez-Rodriguez, M.; Cabeza, O.; Gallego, L. J.; Varela, L. M. MD Simulations of the Formation of Stable Clusters in Mixtures of Alkaline Salts and Imidazolium-Based Ionic Liquids. Journal of Physical Chemistry B 2013, 117 (11), 3207-3220.

50. Kubota, K.; Tamaki, K.; Nohira, T.; Goto, T.; Hagiwara, R. Electrochemical properties of alkali bis(trifluoromethylsulfonyl)amides and their eutectic mixtures. Electrochimica Acta 2010, 55 (3), 1113-1119.

51. Marczewski, M. J.; Stanje, B.; Hanzu, I.; Wilkening, M.; Johansson, P. "Ionic liquids-in-salt" - a promising electrolyte concept for high-temperature lithium batteries? Physical Chemistry Chemical Physics 2014, 16 (24), 12341-12349.

52. Moucka, F.; Nezbeda, I.; Smith, W. R. Molecular Force Field Development for Aqueous Electrolytes: 1. Incorporating Appropriate Experimental Data and the Inadequacy of Simple Electrolyte Force Fields Based on Lennard-Jones and Point Charge Interactions with Lorentz-Berthelot Rules. Journal of Chemical Theory and Computation 2013, 9 (11), 5076-5085.

53. Liu, H. J.; Maginn, E.; Visser, A. E.; Bridges, N. J.; Fox, E. B. Thermal and Transport Properties of Six Ionic Liquids: An Experimental and Molecular Dynamics Study. Industrial \& Engineering Chemistry Research 2012, 51 (21), 7242-7254.

54. Stilling, Fh.; Rahman, A. Improved simulation of liquid water by moleculardynamics. Journal of Chemical Physics 1974, 60 (4), 1545-1557.

55. Rafferty, J. L.; Sun, L.; Siepmann, J. I.; Schure, M. R. Investigation of the driving forces for retention in reversed-phase liquid chromatography: Monte Carlo simulations of solute partitioning between n-hexadecane and various aqueous-organic mixtures. Fluid Phase Equilibria 2010, 290, 25-35. 


\section{Graphical Abstract}

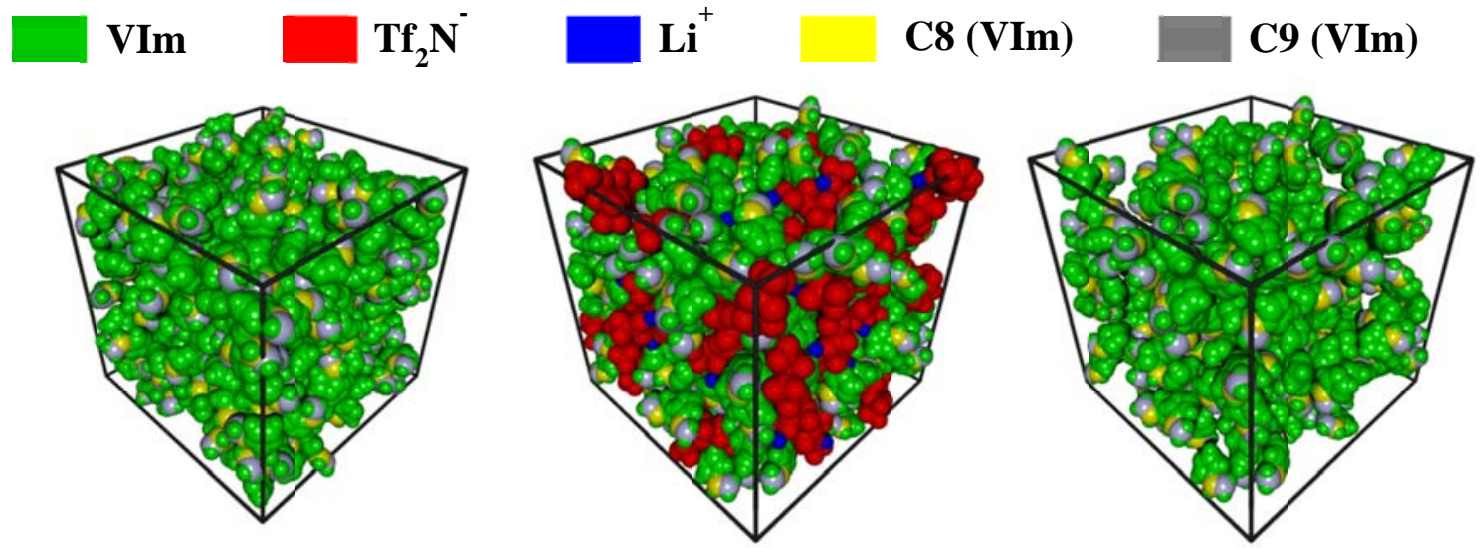

Representative simulation snapshot at $303 \mathrm{~K}$ of: (a) pure VIm system; (b) 3:1 molar mixture of VIm:LiTf $2 \mathrm{~N}$; and (c) 3:1 molar mixture of VIm:LiTf $2 \mathrm{~N}$, with $\operatorname{LiTf}_{2} \mathrm{~N}$ molecules removed for clarity. 